LIVER

\title{
Effect of central corticotropin releasing factor on hepatic circulation in rats: the role of the $\mathrm{CRF}_{2}$ receptor in the brain
}

\author{
M Yoneda, K Nakamura, Y Nakade, M Tamano, T Kono, H Watanobe, T Shimada, H Hiraishi, \\ A Terano
}

See end of article for authors' affiliations

.....................

Correspondence to: $\operatorname{Dr} M$ Yoneda, Department of Gastroenterology, Dokkyo University Śchool of Medicine,

Kitakobayashi 880, Mibu, Tochigi 321-0293, Japan; yoneda@dokkyomed.ac.jp

Revised version received 25 March 2004

Accepted for publication 26 June 2004

\begin{abstract}
Backgrounds: Corticotropin releasing factor (CRF) is distributed in the central nervous system and acts as a neurotransmitter to regulate gastric functions through vagal-muscarinic pathways. We have recently demonstrated that central CRF aggravates experimental acute liver injury in rats. In the present study, the central effect of CRF on hepatic circulation was investigated.

Methods: Hepatic surface perfusion was determined by laser Doppler flowmetry in urethane anaesthetised rats. Portal pressure and portal blood flow was simultaneously monitored. CRF (0.1-4 nmol), urocortin II (a selective $\mathrm{CRF}_{2}$ receptor agonist 2.5-100 pmol), or saline vehicle was injected intracisternally, and changes in hepatic circulation were observed for 120 minutes. We examined the effects of various pretreatments with $\mathrm{K} 41498$, a selective $\mathrm{CRF}_{2}$ receptor antagonist, atropine, 6-hydroxydopamine, hepatic plexus denervation, or hepatic branch vagotomy, respectively.

Results: Intracisternal injection of CRF $(0.2-4 \mathrm{nmol})$ caused a dose dependent decrease in hepatic surface perfusion with a maximum response occurring 60 minutes post injection. Portal pressure was dose dependently elevated and portal blood flow was decreased by intracisternal CRF concurrently with the decrease in hepatic surface perfusion. These changes in hepatic circulation by intracisternal CRF were abolished by 6-hydroxydopamine and hepatic plexus denervation, but not by atropine or hepatic vagotomy. Urocortin II injected intracisternally decreased hepatic surface perfusion and elevated portal pressure at doses within the picomolar range. Intracisternal preadministration of K41498 inhibited the effect of central CRF on the hepatic circulation.

Conclusion: These data suggest that CRF acts in the brain to decrease hepatic surface perfusion and elevate portal pressure through central $\mathrm{CRF}_{2}$ receptor and sympathetic-noradrenergic pathways.
\end{abstract}

onvergent neuroanatomical-neuropharmacological evidence suggests a role for the central and autonomic nervous systems in regulating hepatic functions ${ }^{12}$; however, the involvement of neurotransmitters in the central nervous system to mediate these effects is still poorly understood. In addition to acetylcholine and noradrenaline, neuropeptides have recently been recognised as neurotransmitters and neuromodulators in the central and peripheral nervous system, ${ }^{34}$ and centrally acting neuropeptides have been reported to regulate a variety of physiological functions. ${ }^{5}$ With regard to the hepatobiliary system, the autonomic nervous system affects hepatic metabolism and haemodynamics. ${ }^{167}$ It has been reported that some physiological stressors, electrical stimulation of the hypothalamus, and continuous activation of the sympathetic nerve all enhance liver injury in animal models. ${ }^{8}$ We have recently discovered that central injection of corticotropin releasing factor (CRF) induces marked aggravation of carbon tetrachloride induced acute liver injury in rats. ${ }^{10}$ There is ample evidence that the liver receives abundant innervation, ${ }^{11}$ and the autonomic nervous system influences the hepatic microcirculation in rats. ${ }^{12}$ Hepatic circulation is well recognised as a cytoprotective factor in experimental acute liver damage. ${ }^{13}$ These findings led us to hypothesise that CRF may act in the central nervous system to influence the hepatic circulation through the autonomic nervous system. The present study addressed this question by examining the effect of intracisternal injection of CRF on hepatic circulation in rats. We also attempted to determine the subtype of CRF receptors through which central CRF modulates hepatic circulation as two CRF receptor subtypes, designated $C R F_{1}$ and $\mathrm{CRF}_{2}$, have recently been identified. ${ }^{14}$

\section{MATERIALS AND METHODS \\ Animals}

Male Wistar rats weighing 245-265 g (SLC Co., Shizuoka, Japan) were housed in group cages (four rats each) under the conditions of controlled temperature $\left(22-24^{\circ} \mathrm{C}\right)$ and illumination (12 hour light cycle starting at $6 \mathrm{am}$ ) for at least seven days before experiments. Animals were maintained on standard laboratory chow (Oriental Yeast Co., Tokyo, Japan) and tap water was available ad libitum. Experiments were performed in rats that had been deprived of food but given free access to water for 24 hours until commencement of the study. Protocols describing the use of rats were approved by the Animal Care Committee of Dokkyo University School of Medicine, and were in accordance with the Minister of Education, Culture, Sports, Science, and Technology of Japan Guide for the Care and Use of Laboratory Animals.

\section{Chemicals}

The following substances were used: rat CRF (Peptide Institute, Osaka, Japan), mouse urocortin II (Peptide Institute), K41498 (Sigma Chemical, St Louis, Missouri, USA), atropine methyl nitrate (Sigma), urethane (Sigma), 6-hydrodxydopamine (Sigma), and phenol (Wako Pure Chemical, Osaka, Japan).

\section{Animal preparation and experimental design}

All experiments were performed in rats anaesthetised with urethane $(1.5 \mathrm{~g} / \mathrm{kg}$ intraperitoneally). Rats underwent

Abbreviations: CRF, corticotropin releasing factor 

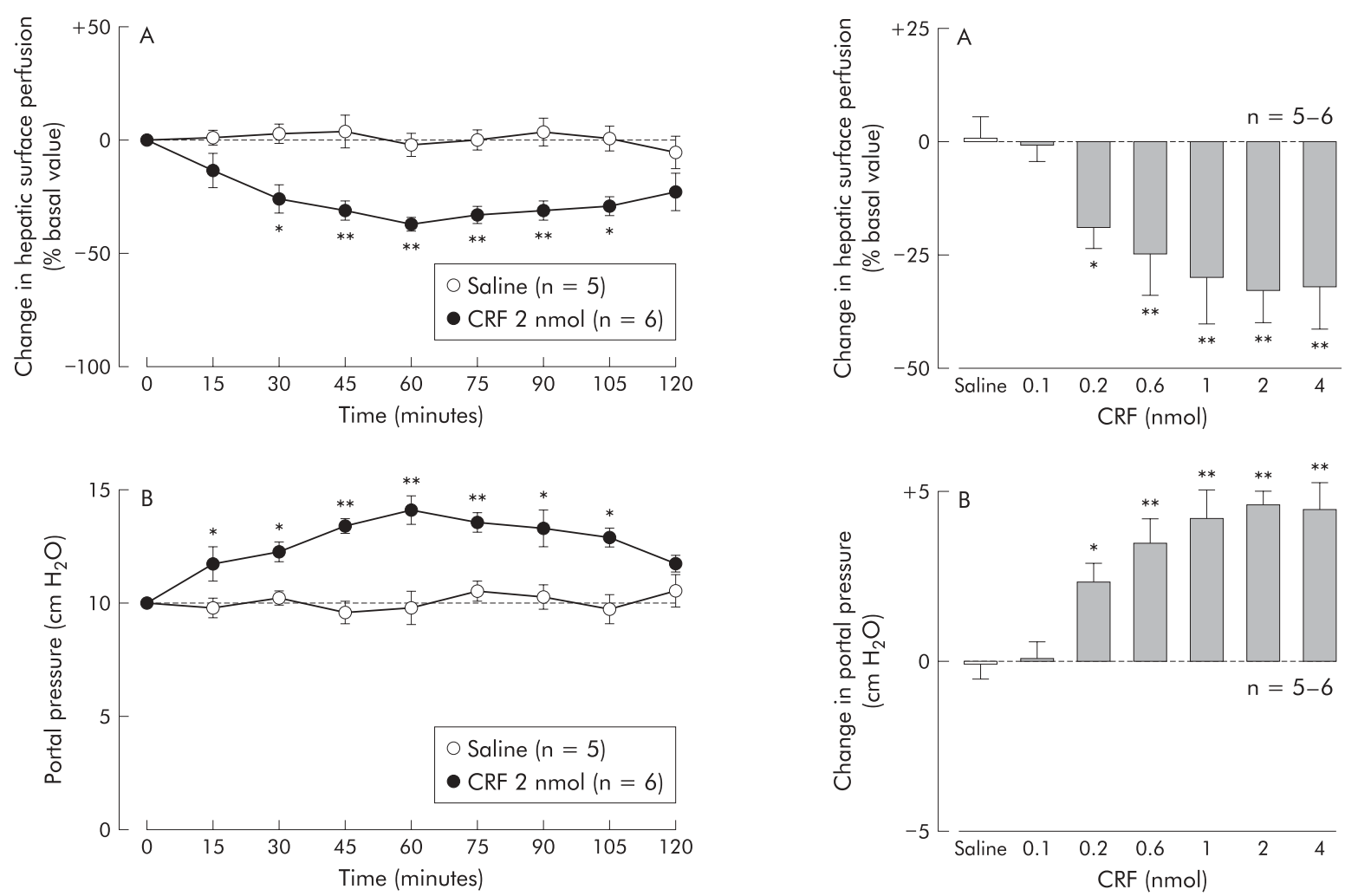

Figure 1 Time course effect of intracisternal injection of corticotropin releasing factor (CRF) on hepatic surface perfusion (A) and portal venous pressure (B). After measurement of a 20 minute basal hepatic surface perfusion and portal pressure by laser Doppler flowmetry and pressure transducer, respectively, CRF (2 nmol) or $0.9 \%$ saline vehicle was injected intracisternally. Change in hepatic surface perfusion and portal pressure was monitored thereafter for 120 minutes. Each point represents the mean (SEM). ${ }^{*} p<0.05,{ }^{* *} p<0.01$ compared with the basal period.

tracheotomy, and PE-260 tubing (Clay Adams, BD, Parsippany, New Jersey, USA) was inserted into the trachea to ensure an airway. The femoral artery was cannulated with PE-50 tubing (Clay Adams, BD), and arterial blood pressure was continuously monitored and recorded using a pressure transducer (Uniflow; Baxter, Valencia, California, USA), a pressure amplifier (PA-001; Star Medical Co., Tokyo, Japan), and a computer (Macintosh G4; Apple Computer, Inc., Cupertino, California, USA) equipped with a data recording and analysis system (MacLab; AD Instruments Pty Ltd, Castle Hill, Australia). Rats were mounted on ear bars of a stereotaxic apparatus (Kopf model 900; David Kopf Instruments, Tujunga, California, USA) and positioned to expose the abdomen. A $3 \mathrm{~cm}$ midline abdominal incision was made, the superior mesenteric vein was cannulated with PE20 tubing, and the tip of the cannula was advanced into the portal trunk. Portal venous pressure was monitored, as described above. A probe (diameter $6 \mathrm{~mm}$, type $\mathrm{H}$; Advance Co. Ltd, Tokyo, Japan) of a laser Doppler flowmeter (ALF 21; Advance Co. Ltd) was placed on the surface of the lateral left lobe of the liver. The flow signal was averaged with a three second time constant and recorded, as described above. Hepatic surface perfusion was expressed relative to the basal level. Body temperature was kept at $37^{\circ} \mathrm{C}$ by external heating and the liver surface was continuously rinsed with $0.9 \%$ saline $\left(37^{\circ} \mathrm{C}, \mathrm{pH} 7.4\right)$ to keep moist.

After the surgical preparation was complete, animals were left undisturbed for 60 minutes for stabilisation of temperature, heart rate, and arterial blood pressure. After observation

Figure 2 Dose related effect of intracisternal corticotropin releasing factor (CRF) on hepatic surface perfusion (A) and portal pressure (B) in urethane anaesthetised rats. After a 20 minute basal measurement, CRF $(0.1,0.2,0.6,1,2$, or $4 \mathrm{nmol})$ or $0.9 \%$ saline vehicle was injected intracisternally. Hepatic surface perfusion and portal pressure were monitored thereafter for 120 minutes. For other details, see legend to fig 1. Each column represents the mean (SEM) per cent change in hepatic surface perfusion at 60 minutes after injection. ${ }^{*} p<0.05$, ${ }^{* *} p<0.01$ compared with the vehicle injection group.

of basal hepatic circulation for 20 minutes, CRF dissolved in $0.9 \%$ saline $(0.1,0.2,0.6,1,2$, or $4 \mathrm{nmol} / \mathrm{rat})$ or $0.9 \%$ saline vehicle was injected intracisternally or intravenously. The accuracy of the intracisternal injection was ascertained by aspiration of cerebrospinal fluid before and after injection of the peptide. After peptide injection, changes in hepatic

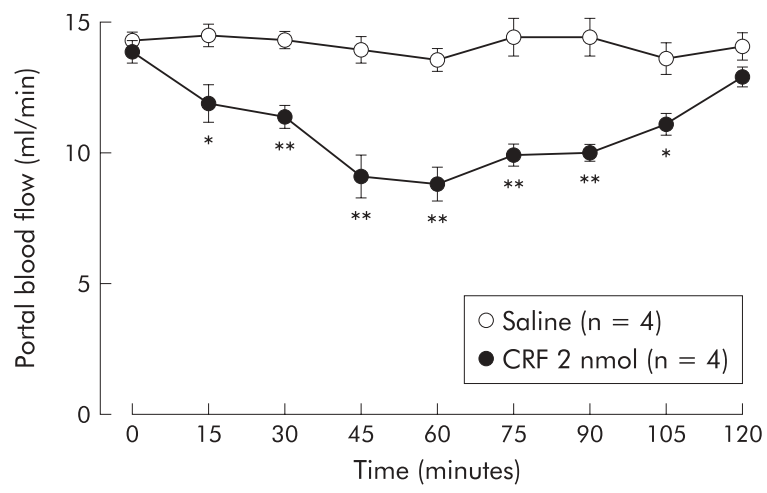

Figure 3 Time course effect of intracisternal injection of corticotropin releasing factor (CRF) on portal blood flow. After measurement of a 20 minute basal portal blood flow by transit time ultrasonic volume flowmetry, CRF ( $2 \mathrm{nmol})$ or $0.9 \%$ saline vehicle was injected intracisternally. Change in portal blood flow was monitored thereafter for 120 minutes. Each point represents the mean (SE). ${ }^{*} p<0.05$, ${ }^{* *} p<0.01$ compared with basal period. 
Table 1 Effect of intravenous injection of corticotropin releasing factor (CRF) on hepatic surface perfusion and portal venous pressure in urethane anaesthetised rats

\begin{tabular}{|c|c|c|c|c|c|c|c|c|c|}
\hline & \multicolumn{9}{|c|}{ Time after intravenous injection (minutes) } \\
\hline & $\overline{0}$ & 15 & 30 & 45 & 60 & 75 & 90 & 105 & 120 \\
\hline \multicolumn{10}{|c|}{ Change in hepatic surface perfusion (\%) } \\
\hline Saline & $100(0)$ & $102(3)$ & $99(3)$ & $102(3)$ & $99(5)$ & $98(6)$ & $99(4)$ & $100(4)$ & $101(4)$ \\
\hline CRF & $100(0)$ & $101(4)$ & $100(4)$ & $101(4)$ & $102(4)$ & $99(4)$ & $98(3)$ & $101(4)$ & $99(3)$ \\
\hline \multicolumn{10}{|c|}{ Portal venous pressure $\left(\mathrm{cm} \mathrm{H}_{2} \mathrm{O}\right)$} \\
\hline Saline & $9.8(0.3)$ & $9.9(0.3)$ & $10.1(0.2)$ & $9.8(0.4)$ & $10.3(0.4)$ & $10.0(0.6)$ & $9.6(0.4)$ & $10.2(0.4)$ & $10.3(0.5)$ \\
\hline CRF & $9.9(0.7)$ & $10.1(0.4)$ & $9.8(0.4)$ & $10.0(0.3)$ & $10.1(0.7)$ & $10.3(0.4)$ & $9.8(0.4)$ & $10.3(0.6)$ & $9.6(0.4)$ \\
\hline
\end{tabular}

Values are mean (SEM) of five rats per group. After a basal observation, saline vehicle or CRF (2 nmol) was injected intravenously. A change in pancreatic blood flow was monitored thereafter for 120 minutes.

surface perfusion and portal venous pressure were monitored for the subsequent 120 minute period. Doses of CRF were selected on the basis of previous studies that reported the central effect of CRF on hepatic functions. ${ }^{10}$ In another experiment, urocortin II $(2.5,5,15,25,50$, or $100 \mathrm{pmol} / \mathrm{rat})$, a selective $\mathrm{CRF}_{2}$ receptor agonist, was injected intracisternally.

\section{Measurement of portal blood flow}

To measure portal blood flow, we employed a transit time ultrasonic volume flowmeter (model SFA211; Advance Co., Ltd, Tokyo, Japan) connected to a $2 \mathrm{~mm}$ specific perivascular flow probe (type 2S; Advance) suitable for the rat portal vein. The probe was placed around the portal vein and the flow signal was averaged with a three second time constant, and recorded using a data recording and analysis computer system, as described above.
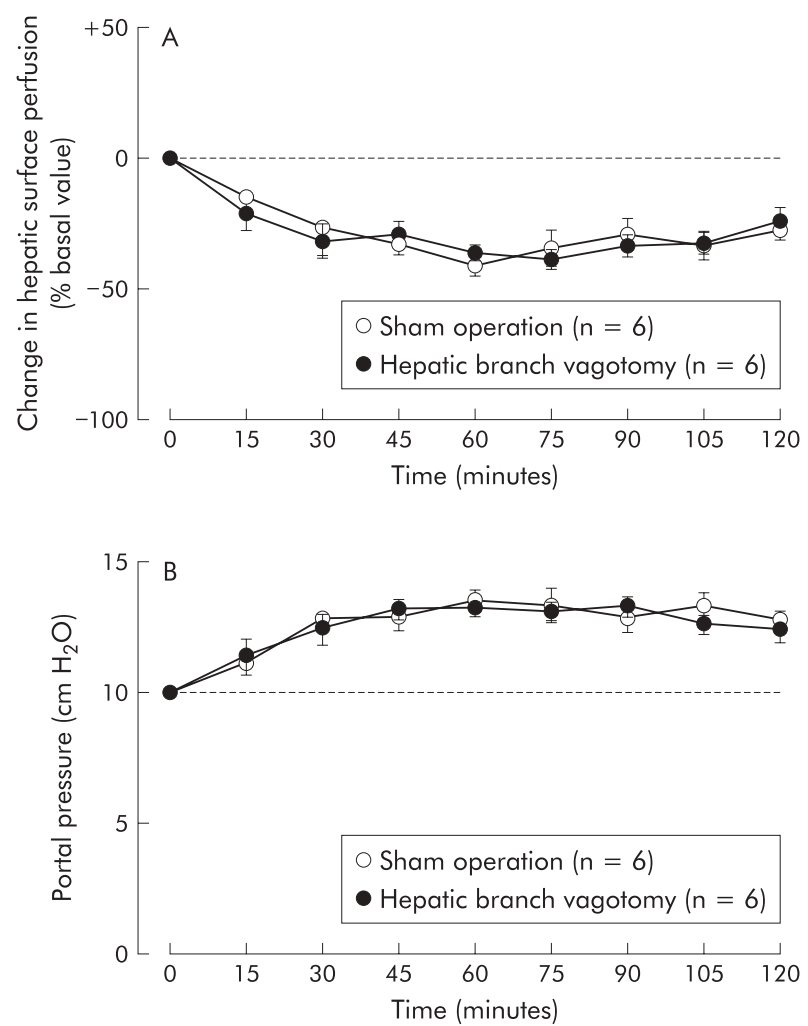

Figure 4 Effect of hepatic branch vagotomy on intracisternal corticotropin releasing factor (CRF) induced alterations in hepatic surface perfusion (A) and portal venous pressure $(B)$ in urethane anaesthetised rats. Hepatic branch vagotomy was performed 120 minutes before intracisternal injection of CRF (2 nmol). For other details, see legend to fig 1. Each point represents the mean (SEM).
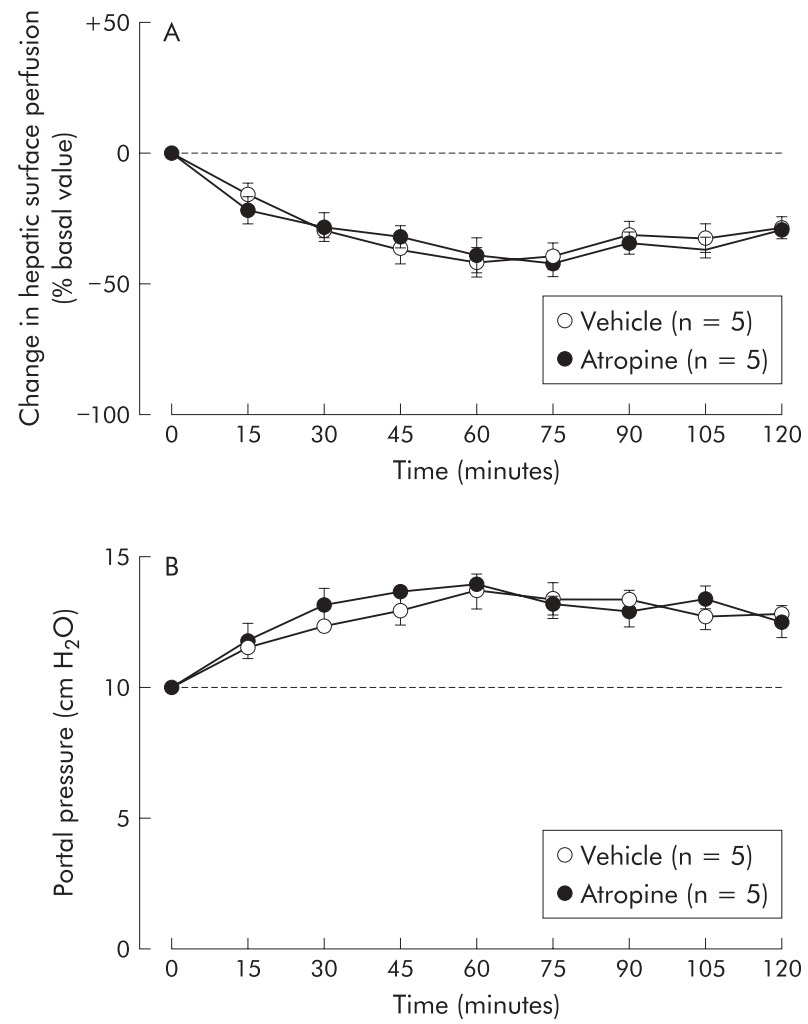

Figure 5 Effect of atropine on intracisternal corticotropin releasing factor (CRF) induced alterations in hepatic surface perfusion (A) and portal venous pressure (B) in urethane anaesthetised rats. Atropine methyl nitrate $(0.15 \mathrm{mg} / \mathrm{kg}$ intraperitoneally) or $0.9 \%$ saline vehicle was injected intraperitoneally 15 minutes before intracisternal injection of CRF $(2 \mathrm{nmol})$. For other details, see legend to fig 1. Each point represents the mean (SEM).

Effects of atropine, 6-hydroxydopamine, hepatic branch vagotomy, hepatic chemical sympathectomy, and $\mathrm{CRF}_{2}$ receptor antagonist, $\mathrm{K} 41498$, on intracisternal CRF induced modulation of hepatic circulation

Atropine methyl nitrate $(0.15 \mathrm{mg} / \mathrm{kg})$ dissolved in $0.9 \%$ saline was injected intraperitoneally in a volume of $1.0 \mathrm{ml} / \mathrm{kg}$, 15 minutes before CRF injection. 6-Hydroxydopamine dissolved in $0.9 \%$ saline was intraperitoneally injected twice ( $100 \mathrm{mg} / \mathrm{kg}$ on the first day, $80 \mathrm{mg} / \mathrm{kg}$ on the fourth day), and intracisternal injection of CRF was performed on the seventh day. Either hepatic plexus denervation or vehicle treatment was performed under pentobarbital anaesthesia (50 mg/kg intraperitoneally; Abbott, North Chicago, Illinois, USA) seven days before the peptide injection, according to the method of Lautt. ${ }^{1}$ Denervation of the hepatic plexus was 

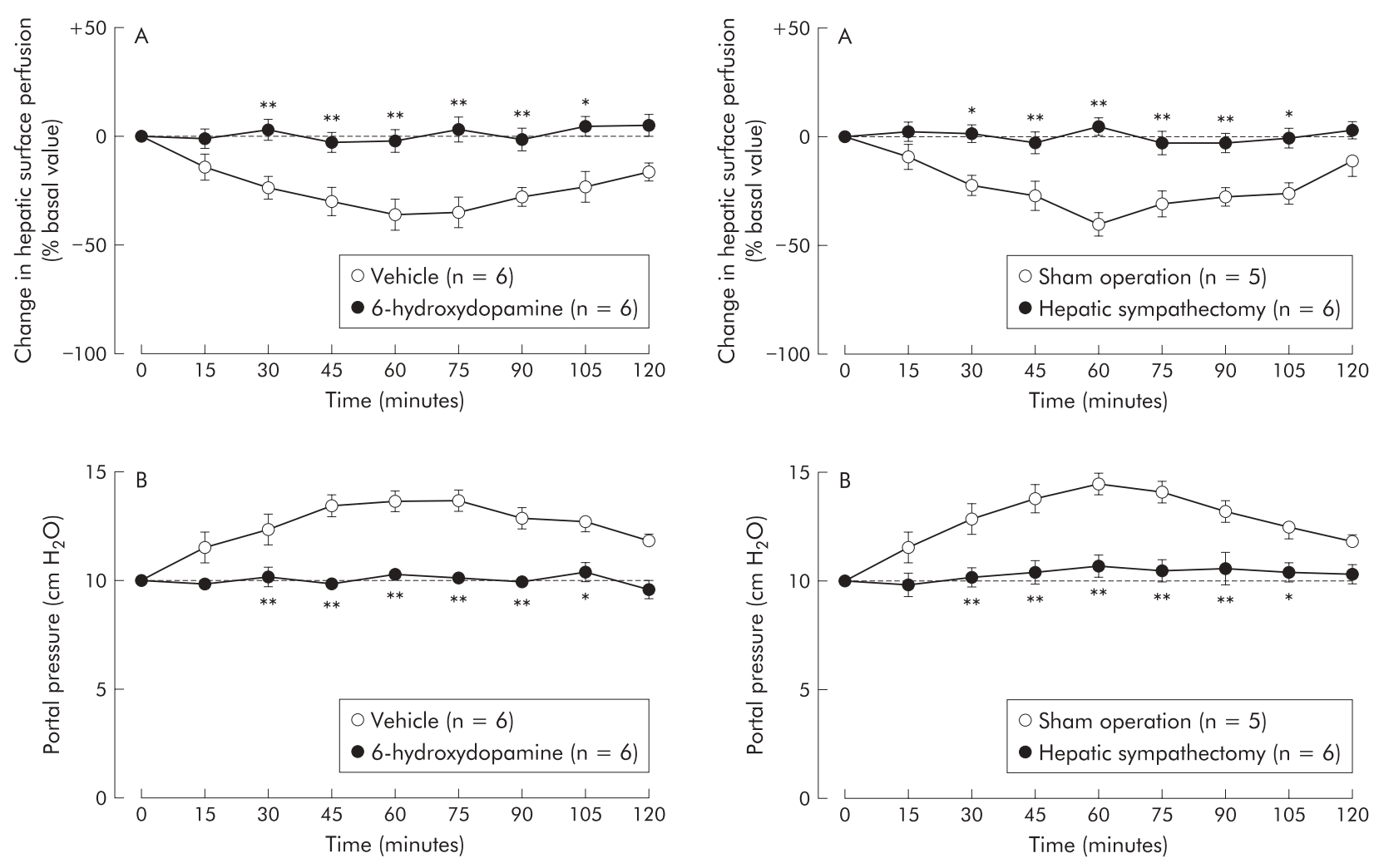

Figure 6 Effect of 6-hydroxydopamine on intracisternal corticotropin releasing factor (CRF) induced alterations in hepatic surface perfusion (A) and portal venous pressure (B) in urethane anaesthetised rats. 6-Hydroxydopamine was intraperitoneally injected seven days before $(100 \mathrm{mg} / \mathrm{kg})$ and four days before $(80 \mathrm{mg} / \mathrm{kg})$ intracisternal injection of CRF (2 nmol). For other details, see legend to fig 1. Each point represents the mean (SEM). ${ }^{*} p<0.05,{ }^{* *} p<0.01$ compared with the vehicle treated group.

carried out rapidly ( $<20$ minutes) by $85 \%$ phenol applied to the region where the hepatic artery and the portal vein run in close apposition. Hepatic branch vagotomy was performed 120 minutes before CRF injection by selective section of the hepatic branch of the vagus nerve branching off from the anterior vagal trunk a few millimetres proximal to the cardia under a dissection microscope. A selective $\mathrm{CRF}_{2}$ receptor antagonist, K41498 (2 nmol), was dissolved in $0.9 \%$ saline and intracisternally administered five minutes before intracisternal CRF injection. The dose of K41498 was selected on the basis of a previous study. ${ }^{15}$

\section{Statistical analysis}

Results are expressed as mean (SEM). Comparison of hepatic surface perfusion, portal blood flow, and portal venous pressure after peptide injection with basal levels was calculated by analysis of variance (ANOVA) repeated measurement. Multiple group comparisons were performed by ANOVA followed by Fisher's protected least significant difference test. A p value $<0.05$ was considered statistically significant.

\section{RESULTS}

\section{Effect of intracisternal CRF on hepatic surface} perfusion and portal venous pressure

Although intracisternal injection of $0.9 \%$ saline vehicle did not alter hepatic surface perfusion in urethane anaesthetised rats assessed by laser Doppler flowmetry (fig 1A), intracisternal CRF ( $2 \mathrm{nmol}$ ) decreased the variable with maximum inhibition (36 (3)\%) occurring 60 minutes post administration. This inhibition of hepatic surface perfusion was sustained for up to 105 minutes after CRF (fig 1A). When

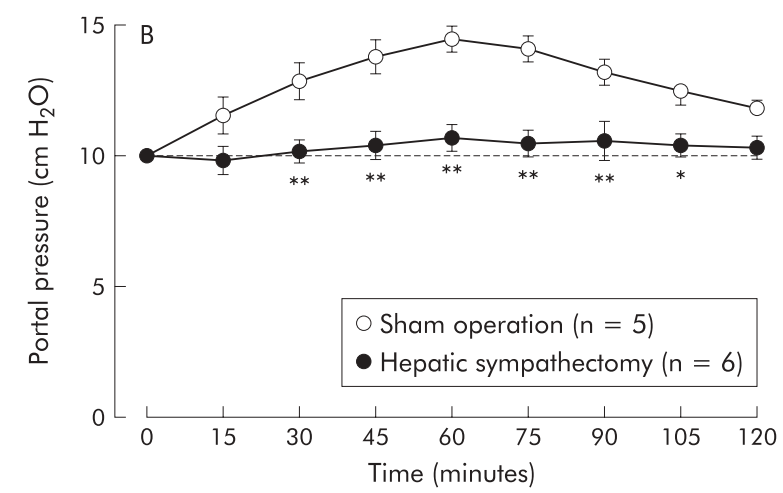

Figure 7 Effect of hepatic plexus denervation on intracisternal corticotropin releasing factor (CRF) induced alterations in hepatic surface perfusion (A) and portal venous pressure $(B)$ in urethane anaesthetised rats. Denervation of hepatic plexus by $85 \%$ phenol was performed seven days before intracisternal injection of CRF ( $2 \mathrm{nmol})$. For other details, see legend to fig 1. Each point represents the mean (SEM). * $p<0.05$, ${ }^{* *} \mathrm{p}<0.01$ compared with the sham operated group.

evaluated by change in hepatic surface perfusion 60 minutes after CRF administration, CRF exerted a dose dependent suppressive effect with doses of 0.2-2 nmol (fig 2A).

Figure $1 \mathrm{~B}$ illustrates the effect of intracisternal CRF ( $2 \mathrm{nmol})$ on the time course of portal venous pressure. Basal portal venous pressure was $9.78(0.34) \mathrm{cm} \mathrm{H}_{2} \mathrm{O}$ and intracisternal saline vehicle injection had no effect. However, portal venous pressure began to significantly increase 15 minutes after intracisternal CRF, reached a maximum at 60 minutes (34 (2)\%), and remained higher than basal levels for up to 105 minutes. These stimulatory effects of intracisternal CRF on portal venous pressure, as estimated 60 minutes after CRF, were dose dependent over the dose range $0.2-2 \mathrm{nmol}$ (fig 2B).

Basal portal blood flow was $13.6(0.7) \mathrm{ml} / \mathrm{min}$ measured by a transit time ultrasonic volume flowmeter. Although intracisternal saline injection did not modify portal blood flow, after intracisternal CRF ( $2 \mathrm{nmol}$ ) injection portal blood flow began to decrease at 15 minutes and reached maximum inhibition (37 (4)\%) at 60 minutes (fig 3).

On the other hand, intravenous injection of CRF ( $2 \mathrm{nmol}$ ) did not significantly affect either hepatic surface perfusion or portal venous pressure (table 1).

Effects of atropine, 6-hydroxydopamine, hepatic branch vagotomy, and hepatic plexus denervation, and $\mathrm{CRF}_{2}$ receptor antagonist, $\mathrm{K} 41498$, on intracisternal CRF induced modulation of hepatic circulation

Alterations in hepatic surface perfusion and portal venous pressure induced by intracisternal CRF ( $2 \mathrm{nmol}$ ) were not 

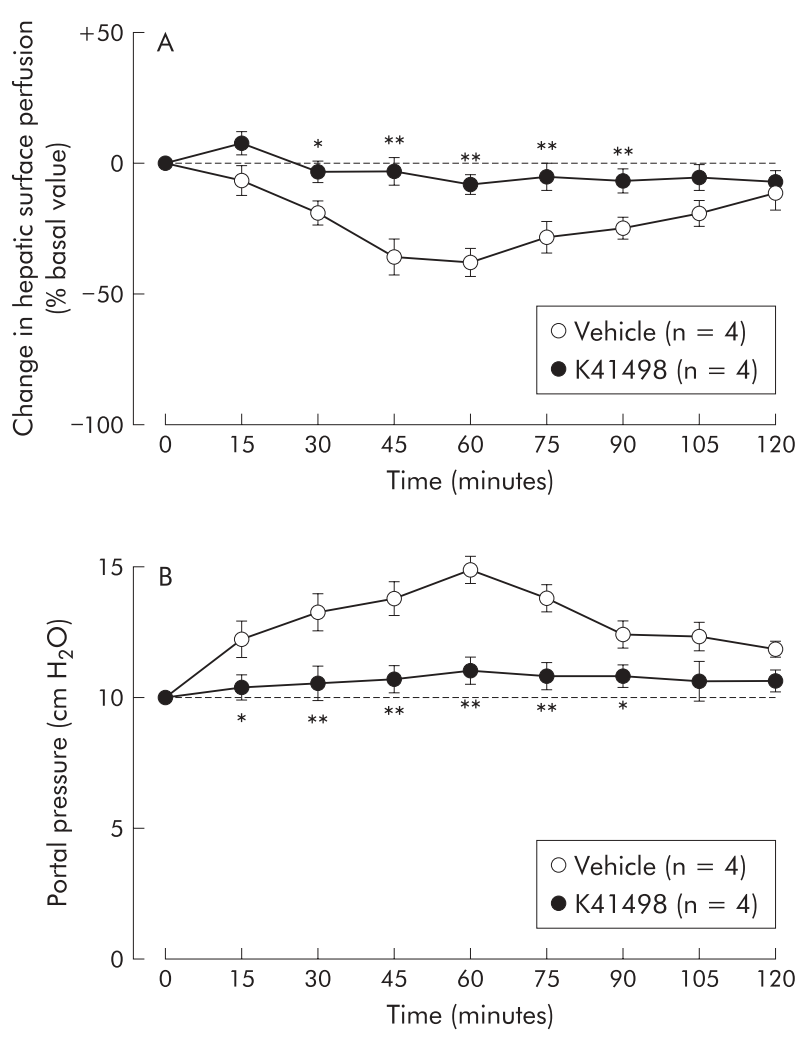

Figure 8 Effect of intracisternal preadministration of the selective $\mathrm{CRF}_{2}$ receptor antagonist K41498 on intracisternal corticotropin releasing factor (CRF) induced alterations in hepatic surface perfusion (A) and portal venous pressure (B) in urethane anaesthetised rats. K41498 $(2 \mathrm{nmol})$ was intracisternally injected five minutes before intracisternal injection of CRF ( $2 \mathrm{nmol})$. For other details, see legend to fig 1. Each point represents the mean (SEM). ${ }^{*} p<0.05,{ }^{* *} p<0.01$ compared with the vehicle treated group.

significantly affected by treatment with either hepatic branch vagotomy or atropine methyl nitrate (figs 4,5 ). On the other hand, both hepatic plexus denervation and 6-hydroxydopamine were effective in abrogating the actions of CRF on hepatic surface perfusion and portal venous pressure (figs 6 , 7). Intracisternal preinjection of K41498 (2 nmol) inhibited the alterations in hepatic surface perfusion and portal venous pressure induced by intracisternal CRF (2 nmol) (fig 8).

\section{Effect of intracisternal CRF on mean arterial blood pressure}

Basal mean arterial blood pressure before CRF injection in urethane anaesthetised rats was $100.6(0.5) \mathrm{mm} \mathrm{Hg}(\mathrm{n}=65)$. Although intracisternal injection of saline did not affect mean arterial blood pressure, intracisternal CRF increased this variable from 15 minutes up to 90 minutes post injection (table 2). This effect of CRF was abolished by 6-hydroxydopamine, but not by atropine, hepatic branch vagotomy, or hepatic plexus denervation (table 2). Basal mean arterial blood pressure was significantly decreased by 6-hydroxydopamine while other pretreatments had no effect (table 2).

\section{Effect of intracisternal urocortin II on hepatic surface perfusion, portal venous pressure, and mean arterial blood pressure}

Intracisternal urocortin II decreased hepatic surface perfusion and elevated portal venous pressure in a dose dependent manner, with doses ranging from 5 to 50 pmol, assessed 60 minutes post injection (fig 9). Urocortin II exerted its maximal effects on both hepatic surface perfusion (37 (3)\%) and portal venous pressure (36 (4)\%) at a dose of 50 pmol, as evaluated 60 minutes post injection. Urocortin II had no effect on mean arterial blood pressure when given at a dose of 50 pmol (table 2).

\section{DISCUSSION}

In the present study, we have demonstrated that CRF, injected intracisternally, decreased hepatic surface perfusion in urethane anaesthetised rats, as determined by laser Doppler flowmetry, a device capable of detecting a relative change in regional tissue blood flow. Intracisternal CRF ( $2 \mathrm{nmol}$ ) significantly decreased hepatic surface perfusion with a maximal response at 60 minutes, and this inhibition persisted for up to 105 minutes after CRF administration. Doses ranging from 0.2 to $4 \mathrm{nmol}$ induced a relative decrease in hepatic surface perfusion assessed 60 minutes after CRF injection. As the $4 \mathrm{nmol}$ dose of CRF did not decrease hepatic surface perfusion further it seems that $2 \mathrm{nmol}$ of the peptide

Table 2 Effect of intracisternal corticotropin releasing factor (CRF) on mean arterial pressure in urethane anaesthetised rats

\begin{tabular}{|c|c|c|c|c|c|c|c|c|c|}
\hline & \multicolumn{9}{|c|}{ Time after intracisternal injection (minutes) } \\
\hline & 0 & 15 & 30 & 45 & 60 & 75 & 90 & 105 & 120 \\
\hline \multicolumn{10}{|l|}{ No treatment } \\
\hline Saline & 101 (3) & $99(7)$ & $102(5)$ & $100(6)$ & $102(5)$ & $99(3)$ & $101(2)$ & 101 (3) & $101(2)$ \\
\hline CRF & $98(4)$ & $105(4)^{*}$ & $108(5)^{*}$ & $111(4)^{*}$ & $107(4)^{*}$ & $106(5)^{*}$ & $105(4)^{*}$ & $102(7)$ & $99(6)$ \\
\hline Urocortin II & 101 (4) & $99(3)$ & $102(3)$ & $100(2)$ & $102(2)$ & 99 (4) & $102(3)$ & 99 (4) & $102(5)$ \\
\hline \multicolumn{10}{|l|}{ Vagotomy } \\
\hline Saline & $102(3)$ & $98(3)$ & $99(4)$ & 101 (3) & $101(2)$ & 101 (3) & $99(4)$ & $98(4)$ & $101(3)$ \\
\hline CRF & 99 (4) & $106(3)^{*}$ & $109(4)^{*}$ & $112(6)^{*}$ & $109(4)^{*}$ & $107(3)^{*}$ & $106(3)^{*}$ & $101(3)$ & $98(2)$ \\
\hline \multicolumn{10}{|l|}{ Atropine } \\
\hline Saline & $98(3)$ & $101(3)$ & $101(4)$ & $101(4)$ & $102(4)$ & $98(3)$ & $101(2)$ & $99(4)$ & $100(3)$ \\
\hline CRF & 101 (4) & $106(4)^{*}$ & $110(6)^{*}$ & $109(4)^{*}$ & $108(5)^{*}$ & $108(4)^{*}$ & $107(4)^{*}$ & 104 (4) & $102(2)$ \\
\hline \multicolumn{10}{|c|}{ Hepatic plexus denervation } \\
\hline Saline & $101(2)$ & $102(3)$ & $99(5)$ & $102(3)$ & $101(3)$ & $98(5)$ & $99(3)$ & $102(4)$ & $99(5)$ \\
\hline CRF & 99 (4) & $104(2)^{*}$ & $109(4)^{*}$ & $108(4)^{*}$ & $110(5)^{*}$ & $107(4)^{*}$ & $106(4)$ & $101(5)$ & $99(3)$ \\
\hline \multicolumn{10}{|c|}{ 6-hydroxydopamine } \\
\hline Saline & $72(4)$ & $70(4)$ & $68(3)$ & $70(4)$ & $72(3)$ & $69(4)$ & $68(4)$ & $70(3)$ & $70(2)$ \\
\hline CRF & 69 (3) & $70(3)$ & $69(5)$ & $71(3)$ & $69(3)$ & $68(3)$ & $69(5)$ & $71(4)$ & $72(4)$ \\
\hline
\end{tabular}

Values are mean (SEM) mean arterial pressure $(\mathrm{mm} \mathrm{Hg})$, five rats per group.

After the basal observation, saline vehicle, CRF $(2 \mathrm{nmol})$, or urocortin II $(50$ pmol) was injected intracisternally. Systemic arterial blood pressure was monitored thereafter for 120 minutes. Hepatic branch vagotomy was performed 120 minutes before, atropine methyl nitrate $(0.15 \mathrm{mg} / \mathrm{kg}$ intraperitoneally) was injected 15 minutes before, hepatic plexus denervation by $85 \%$ phenol was performed seven days before, and 6 -hydroxydopamine was administered seven days before $(100 \mathrm{mg} / \mathrm{kg})$ and four days before $(80 \mathrm{mg} / \mathrm{kg})$ intracisternal injection of peptide.

${ }^{*} \mathrm{p}<0.05$ compared with the respective basal period. 

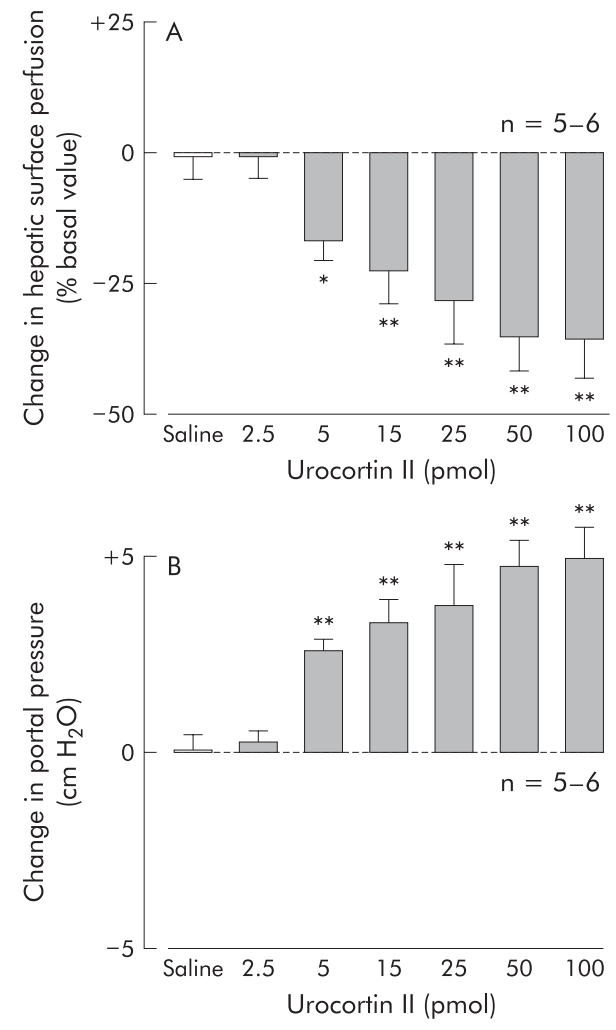

Figure 9 Effect of intracisternal urocortin II on hepatic surface perfusion (A) and portal pressure (B) in urethane anaesthetised rats. After a 20 minute basal measurement, urocortin II $(2.5,5,15,25,50$, or $100 \mathrm{pmol}$ ) or $0.9 \%$ saline vehicle was injected intracisternally. Hepatic surface perfusion was monitored thereafter for 120 minutes. For other details, see legend to fig 1. Each column represents the mean (SEM) per cent change in hepatic surface perfusion 60 minutes after injection. ${ }^{*} p<0.05,{ }^{* *} p<0.01$ compared with the vehicle injection group.

already exerted maximal inhibition. In contrast, $2 \mathrm{nmol}$ of CRF given intravenously did not affect hepatic surface perfusion, which strongly suggests that intracisternal CRF acts in the central nervous system, and not in the periphery, to affect hepatic surface perfusion.

We further examined the pathways through which CRF decreases hepatic surface perfusion. Previous reports have shown that central CRF affects peripheral organs, at least in part via the autonomic nervous system. ${ }^{16}$ Our previous studies have also demonstrated that exogenous and endogenous CRF in the central nervous system aggravate experimental acute liver injury through sympatheticnoradrenergic nervous pathways. ${ }^{10}{ }^{17}$ Furthermore, central injection of CRF stimulates sympathetic nerve activity, ${ }^{18}$ and electrical stimulation of the hepatic sympathetic nerves decreases hepatic blood flow. ${ }^{19}$ In the present study, inhibition of hepatic surface perfusion by intracisternal CRF was completely abolished by denervation of the hepatic plexus with $85 \%$ phenol and 6-hydroxydopamine pretreatment, whereas hepatic branch vagotomy or atropine methyl nitrate treatment had no effect. As treatment of the hepatic plexus with phenol is known to predominantly denervate the hepatic sympathetic nerve and 6-hydroxydopamine chemically depletes noradrenergic nerve fibres via biosynthetic adrenergic intermediates, ${ }^{1}$ our data suggest that CRF acts centrally to decrease hepatic surface perfusion in rats via the sympathetic-noradrenergic nervous system.

The hepatic circulation is regulated by multiple factors. ${ }^{20}$ The liver is perfused by two main blood supplies; the portal vein and hepatic artery. The liver sinusoid is also considered to regulate hepatic blood flow. In agreement with previous reports, ${ }^{21}$ we currently observed a rise in mean arterial blood pressure after intracisternal CRF, and this elevation in blood pressure was abolished by 6-hydroxydopamine pretreatment. Although the CRF induced decrease in hepatic surface perfusion was eliminated by hepatic plexus denervation, this treatment was without effect on central CRF induced stimulation of arterial blood pressure. Furthermore, urocortin II, a $C_{2 R}$ receptor agonist, decreased hepatic surface perfusion but did not influence systemic arterial blood pressure. This finding is consistent with a previous study reporting that the central CRF induced elevation of blood pressure is mediated through the $\mathrm{CRF}_{1}$ receptor ${ }^{22}$; peripheral haemodynamic effects of CRF are suggested to be related to the $\mathrm{CRF}_{2}$ receptor. $^{23}$ It is unlikely that the central CRF induced decrease in hepatic surface perfusion is secondary to altered systemic blood pressure. In the present study, we measured portal venous pressure after intracisternal CRF and found that CRF elevated portal venous pressure concurrently with a decrease in hepatic surface perfusion. Moreover, both the decrease in hepatic surface perfusion and increase in portal venous pressure induced by intracisternal CRF were abolished by 6-hydroxydopamine pretreatment and hepatic plexus denervation by phenol. Moreover, portal blood flow, measured by a transit time ultrasonic volume flowmeter, was decreased by intracisternal injection of CRF, synchronised with the alternation in hepatic surface perfusion. From these results, we suggest that changes in portal, sinusoidal, or presinusoidal resistance may play an important role in the central CRF induced hepatic hyporaemia. This is consistent with a previous report that electrical stimulation of hepatic plexus and noradrenaline infusion both increase portal venous pressure in the perfused rat liver. ${ }^{24}$

To date, two CRF receptor subtypes, designated $\mathrm{CRF}_{1}$ and $\mathrm{CRF}_{2}$, have been identified by molecular cloning from distinct genes in the rat and humans. ${ }^{14}$ Recent pharmacological studies have demonstrated distinct roles in the regulation of gastrointestinal organs. Central CRF induced inhibition of gastric emptying of a solid nutrient meal may be mediated by interaction with the $\mathrm{CRF}_{2}$ receptor while stimulation of colonic motility by central CRF is possibly via the $\mathrm{CRF}_{1}$ receptor. ${ }^{25}$ Urocortin II and urocortin III are novel members of the CRF family that have recently been identified from the human genome database and from homologous mouse gene. ${ }^{26}{ }^{27}$ Both urocortin II and urocortin III bind selectively to the $\mathrm{CRF}_{2}$ receptor while urocortin has equal affinity for $\mathrm{CRF}_{1}$ and $\mathrm{CRF}_{2}$. CRF displays a higher affinity for the $\mathrm{CRF}_{1}$ than the $\mathrm{CRF}_{2}$ receptor. ${ }^{25}{ }^{26}$ In the present study, $50 \mathrm{pmol}$ of urocortin II injected intracisternally exerted a maximal effect on both hepatic surface perfusion and portal venous pressure while a $2 \mathrm{nmol}$ dose was necessary to provoke maximal changes in these variables under identical experimental conditions. When compared on a molar basis, these results suggest that urocortin II is 40 -fold more potent than CRF in decreasing hepatic surface perfusion and elevating portal venous pressure when injected intracisternally. Moreover, the selective $\mathrm{CRF}_{2}$ receptor antagonist, K41498, inhibited the effect of central CRF on the hepatic microcirculation in the present study. These data strongly suggest that the $\mathrm{CRF}_{2}$ receptor may play a pivotal role in mediating the suppressive actions of central CRF on the hepatic circulation and are consistent with our previous reports that demonstrated a relatively predominant role for the $\mathrm{CRF}_{2}$ receptor in the central CRF induced aggravation of carbon tetrachloride induced acute liver injury in rats. ${ }^{28}$ On the other hand, urocortin is reported to act peripherally to increase hepatic blood flow. ${ }^{29}$ Taken together, it is interesting to note that the same peptide induces opposing haemodynamic effects on the liver depending on the site at which it acts. 
CRF receptors are widely distributed in the central nervous system. Our present data do not tell us where in the brain CRF and urocortin II act to modulate the hepatic circulation. To address this issue it would be helpful to determine the effects of these peptides when microinjected into various brain nuclei that are potentially important in regulating the hepatobiliary system. Our findings that chemical sympathectomy and 6-hydroxydopamine were effective in abrogating the actions of CRF on the hepatic circulation may implicate the hypothalamus as a putative site of action for CRF. This is because the hypothalamus is known to play a primary role in regulating sympathetic nerve outflow.

The liver is known to be richly innervated, ${ }^{11}$ and there is abundant evidence that the central and autonomic nervous systems play important roles in regulating hepatic functions, including the hepatic microcirculation. ${ }^{12}$ However, little is known about the involvement of central neuropeptides in modulating hepatic function. In the present study, we found that central administration of CRF inhibited hepatic surface perfusion and elevated portal venous pressure through sympathetic and noradrenergic nerve pathways, and speculate that CRF may act in the brain as a neurotransmitter in the central modulation of the hepatic circulation. To date, we have shown that central neuropeptide $\mathrm{Y}$ stimulates bile secretion through vagal nerves, and central thyrotropin releasing hormone enhances the hepatic circulation and proliferation, and also induces hepatic cytoprotection. ${ }^{30-34}$ It is interesting to note that several neuropeptides act in the central nervous system and play significant roles in the physiological and pathophysiological regulation of hepatic functions involving different autonomic nervous pathways.

In summary, our data demonstrate that CRF injected intracisternally acts in the brain to induce inhibition of hepatic surface perfusion concurrently with an elevation in portal venous pressure. Our results suggest that these CRF actions may be mediated through the central $\mathrm{CRF}_{2}$ receptor and sympathetic-noradrenergic pathways.

\section{ACKNOWLEDGEMENT}

Supported in part by the Grant-in-Aid for Scientific Research from the Japan Society for the Promotion of Science (No15590681) and the Japan Smoking Health Foundation

\section{Authors' affiliations}

M Yoneda, M Tamano, T Shimada, H Hiraishi, A Terano, Department of Gastroenterology, Dokkyo University School of Medicine, Mibu, Japan K Nakamura, Y Nakade, T Kono, Second Department of Medicine and Surgery, Asahikawa Medical College, Japan

H Watanobe, Clinical Research Centre, International University of Health and Welfare, Japan

Conflict of interest: None declared.

\section{REFERENCES}

1 Lautt WW. Afferent and efferent neural roles in liver function. Prog Neurobiol 1983;21:323-48

2 Shimazu T, Matsushita H, Ishikawa K. Cholinergic stimulation of the rat hypothalamus: effects of liver glycogen synthesis. Science 1976;194:535-6.

3 Brown M, Taché Y, Fisher D. Central nervous system action of bombesin: mechanism to induce hyperglycemia. Endocrinology 1979;105:660-5.

4 Brown M, Rivier J, Vale W. Somatostatin: central nervous system actions on glucoregulation. Endocrinology 1979;104:1709-15.

5 Taché $\mathrm{Y}$, Yang $\mathrm{H}$. Brain regulation of gastric acid secretion by peptides. Sites and mechanisms of action. Ann N Y Acad Sci 1990;597:128-45.
6 Gardemann A, Puschel G, Jungermann K. Nervous control of liver metabolism and hemodynamics. Eur J Biochem 1992;207:399-411.

7 Iwai M, Saheki S, Ohta Y, et al. Footshock stress accelerates carbon tetrachloride-induced liver injury in rats: implication of the sympathetic nervous system. Biomed Res 1986;7:145-54.

8 Iwai M, Shimazu T. Effects of ventromedial and lateral hypothalamic stimulation on chemically-induced liver injury in rats. Life $\mathrm{Sci}$ 1988;42:1833-40

9 Hsu CT. The role of the sympathetic nervous system in promoting liver cirrhosis induced by carbon tetrachloride, using the essential hypertensive animal (SHR). J Auton Nerv Syst 1992;37:163-73.

10 Yokohama S, Yoneda M, Nakamura K, et al. Effect of central corticotropin releasing factor on carbon tetrachloride-induced acute liver injury in rats. Am J Physiol 1999;276:G622-8.

11 Rogers RC, Hermann GE. Central connections of the hepatic branch of the vagus nerve: a horseradish peroxidase histochemical study. J Auton Nerv Syst 1983;7:165-74.

12 Koo A, Liang I. Microvascular filling pattern in rat liver sinusoids during vagal stimulation. J Physiol (Lond) 1979:295:191-9.

13 Goto M, Takei Y, Kawano S, et al. Endothelin-1 is involved in the pathogenesis of ischemia/reperfusion liver injury by hepatic microcirculatory disturbances. Hepatology 1994; 19:675-81.

14 Chalmers DT, Lovenberg TW, Grigoriadis DE, et al. Corticotrophin-releasing factor receptors: from molecular biology to drug design. Trends Pharmacol Sci $1996 ; 17: 166-72$

15 Lawrence AJ, Krstew EV, Dautzenberg FM, et al. The highly selective CRF2 receptor antagonist $\mathrm{K} 41498$ binds to presynaptic $\mathrm{CRF}_{2}$ receptors in rat brain Br J Pharmacol 2002; 136:896-904.

16 Taché YMM-H, Turkelson CM. Central nervous system action of corticotropinreleasing factor to inhibit gastric emptying in rats. Am J Physiol 1987; 253:G241-5.

17 Nakade Y, Yoneda M, Nakamura K, et al. Involvement of endogenous CRF in carbon tetrachloride-induced acute liver injury in rats. Am J Physiol 2002;282:R1782-8.

18 Katafuchi T, Ichijo T, Hori T. Sequential relationship between actions of CRF and PGE2 in the brain on splenic sympathetic nerve activity in rats. J Auton Nerv Syst 1997:67:200-6.

19 Kurosawa M, Unno T, Aikawa Y, et al. Neural regulation of hepatic blood flow in rats: an in vivo study. Neurosci Lett 2002;321:145-8.

20 Lautt W, Greenway C. Conceptual review of the hepatic vascular bed. Hepatology 1987; 5:952-63.

21 Overton JM, Fisher LA. Central nervous system actions of corticotropinreleasing factor on cardiovascular function in the absence of locomotor activity. Regul Pept 1989;25:315-24.

22 Nijsen MJ, Croiset G, Stam R, et al. The role of the CRH type 1 receptor in autonomic responses to corticotropin- releasing hormone in the rat. Neuropsychopharmacology 2000;22:388-99.

23 Coste SC, Kesterson RA, Heldwein KA, et al. Abnormal adaptations to stress and impaired cardiovascular function in mice lacking corticotropin-releasing hormone receptor-2. Nature Genet 2000;24:403-9.

24 Mathie RT, Ralevic V, Burnstock G. Portal vascular responsiveness to sympathetic stimulation and nitric oxide in cirrhotic rats. J Hepatol 1996;25:90-7

25 Martinez V, Taché Y. Role of CRF receptor 1 in central CRF-induced stimulation of colonic propulsion in rats. Brain Res 2001 893:29-35.

26 Lewis K, Li C, Perrin MH, et al. Identification of urocortin III, an additional member of the corticotropin-releasing factor (CRF) family with high affinity for the CRF2 receptor. Proc Natl Acad Sci U S A 2001;98:7570-5.

27 Reyes TM, Lewis K, Perrin MH, et al. Urocortin II: a member of the corticotropin-releasing factor (CRF) neuropeptide family that is selectively bound by type 2 CRF receptors. Proc Nat Acad Sci U S A 2001;98:2843-8.

28 Yokohama S, Yoneda $\mathrm{M}$, Watanobe $\mathrm{H}$, et al. Effect of central urocortin on carbon tetrachloride-induced acute liver injury in rats. Neurosci Lett 2001;313:149-52

29 Abdelrahman AM, Pang CC. Regional haemodynamic effects of urocortin in the anaesthetized rat. Eur J Pharmacol 2003;466:317-21.

30 Tamori K, Yoneda M, Nakamura K, et al. Effect of intracisternal thyrotropinreleasing hormone on hepatic blood flow in rats. Am J Physiol 1998;274:G277-82.

31 Yoneda M, Hashimoto T, Nakamura K, et al. Thyrotropin-releasing hormone in the dorsal vagal complex stimulates hepatic blood flow in rats. Hepatology, 2003 38, 38:1500-7

32 Sato Y, Yoneda M, Nakamura K, et al. Protective effect of central thyrotropinreleasing hormone on carbon tetrachloride-induced acute hepatocellular necrosis in rats. J Hepatol 2003;39:47-54.

33 Yoneda M, Tamori K, Sato Y, et al. Central thyrotropin-releasing hormone stimulates hepatic DNA synthesis in rats. Hepatology 1997;26:1203-8.

34 Yoneda M, Nakamura K, Yokohama S, et al. Neuropeptide Y stimulates bile secretion via $Y 1$ receptor in the left dorsal vagal complex in rats. Hepatology 1998;28:670-6. 